Recorregut de recerca geològica i mineralògica pel departament de I'Aude des de Quilhan I Quillan a Esperesan / Espéraza, Coisan / Couizza, Limous / Limoux i a Carcassona / Carcassonne

Josep Maria Mata-Perelló

Joaquim Sanz Balagué

TERRA

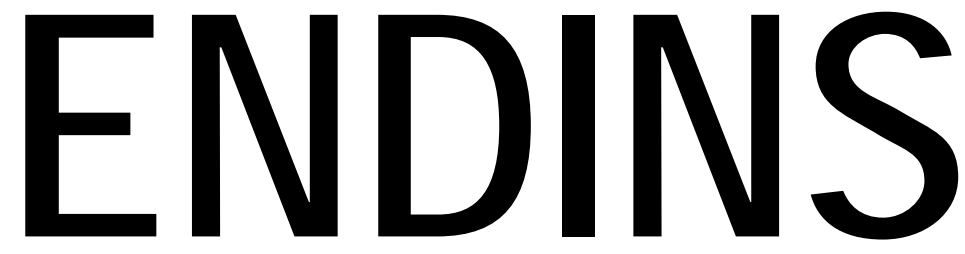

REVISTA DE GEOLOGIA

n. 3

SETEMBRE 2015 


\title{
RECORREGUT DE RECERCA GEOLÒGICA I MINERALÒgICA PEL DEPARTAMENT DE L'AUDE : DES DE QUILHAN I QUILLAN A ESPERESAN / ESPÉRAZA, COISAN I COUIZZA, LIMOUS I LIMOUX I A CARCASSONA I CARCASSONNE
}

\author{
Josep Maria Mata-Perelló \\ Museu de geologia Valentí Masachs, Escola Politècnica Superior d'Enginyeria de Manresa \\ (EPSEM), Universitat Politècnica de Catalunya · BarcelonaTech (UPC), 08272 Manresa, Spain
}

\section{Joaquim Sanz Balagué}

Departament d'Enginyeria Minera i Recursos Naturals (EMRN), Escola Politècnica Superior d'Enginyeria de Manresa (EPSEM), Universitat Politècnica de Catalunya . BarcelonaTech (UPC), 08272 Manresa, Spain

Paraules clau: Patrimoni geològic i miner; Mines de ferro; Cerdanya; materials neògens ; Morfologia glacial

\section{Resum}

Recorregut realitzat el 8 de juliol del 2014. El recorregut del present itinerari, es desenvoluparà a cavall de dues unitats geològiques netament diferenciades: el Sistema Pirinenc i la Depressió d'Aquitanie. Així, el recorregut s'iniciarà a la Zona Nord - Pirinenca o Pirineu Septentrional (integrant del Sistema Pirinenc). Tot seguit, prop d'Esperasan / Espérasa s'entrarà a la denominada Zone Subpirineaica, per on anirem transitant fins prop de Limous / Limoux. Després ja s'entrarà a la Depressió d'Aquitànie, per on es desenvoluparà la resta d'aquest recorregut

Per d'altra banda, aquest recorregut es desenvoluparà íntegrament pel Departament de l'Aude, des de Quilhan / Quillan fins a Carcassona / Carcassonne. 


\section{ADVERTIMENT PREVI}

Com en altres recorreguts de RECERCA GEOLÒGICA I MINERALÒGICA ..., si es disposa del temps suficient, poden efectuar-se passant per totes les parades i filloles. En cas contrari, recomanem prescindir de les anomenades PARADES - CONDICIONALS.

Cal dir també, que en aquest itinerari no ens trobarem davant de camins forestals en molt mal estat de conservació.

I, finalment, en qualsevol cas, cal tenir sempre una cura molt especial de respecte a la natura, al llarg de tot el recorregut; de l'itinerari.

\section{OBJECTIUS FONAMENTALS D’AQUEST ITINERARI}

A través d'aquest itinerari geològico-mineralògic, s'intentaran d'aconseguir els següents objectius, acord amb el sentit de la marxa del recorregut.

1.- Estudi i observació de la Zona Nord - Pirinenca (corresponent als antigament denominats Prepirineus Septentrionals) per la qual es circularà al llarg del primer tram del recorregut, entre Quilhan / Quillan i Esperasan / Espérasa. En aquest trajecte es trobaran afloraments dels materials mesozoics, fonamentalment del Cretàcic.

2.- Observació, dels materials mesozoics (fonamentalment del Cretàcic), que constitueixen aquesta Zona Nord - Pirinenca, segons els indrets del recorregut, tot i que predominen sempre els darrers, en aquest itinerari.

3.- Observació del sector corresponent a la denominada Zona Sudpirinenca. Aquesta zona la travessarem entre Esperasan / Espérasa i Limous / Limoux. En aquest trajecte trobarem diverses escates i veurem afloraments paleozoics (del Carbonifer i Devonià) del mesozoic (del Cretàcic) i del Cenozoic (Eocè).

4.- Estudi, de les relacions entre les dues unitats geològiques esmentades: així, poc després de l'inici del recorregut, es tallarà l'encavalcament de Quillan, el qual posa en contacte la Zona Nord - Pirinenca i la Zona Sudpirinenca

5.- Observació de les diferents estructures que trobarem dintre de la denominada Zona Sudpirinenca. Aquestes de Sud a Nord seran les següents: Sinclinal de Rennes - les Bains, Anticlinal de Puivert - Cardou, Sinclinal de Couiza - Arques i Anticlinal d'Alet.

6.- Observació dels diferents indrets relacionats amb el patrimoni geològic i miner, que anirem trobant al llarg del recorregut del present itinerari. 


\section{ANTECEDENTS BIBLIOGRÀFICS}

En relació amb el recorregut del present itinerari, no con coneixem l'existència de cap altre que segueixi aquest mateix recorregut.

Farem esment de dos treballs de caràcter regional com són els publicats pel BRGM (1970a, 1970b, 1970c, 1989 i 1993).

Tots aquests treballs, i d'altres, figuraran degudament relacionats per ordre alfabètic, i per data de publicació, dintre de l'apartat d'aquest treball dedicat a les REFERÈNCIES BIBLIOGRÀFIQUES, al gual ens adrecem.

\section{RECORREGUT DE L'ITINERARI}

El recorregut d'aquest itinerari el començarem a la població de Quilhan / Quillan, per on podem fer una aturada, si s'escau. Després, seguirem, baixant per la val del riu Aude, per Esperasan / Espérasa, per on farem una nova aturada.

Tot seguit, per l'esmentada carretera arribarem a Cuisan / Couiza, des d'on caldrà anar cap al poble d'Alet / Alet - les Bains, per on farem una nova aturada, si s'escau. Tot seguit continuarem cap el Nord, amb la finalitat d'arribar a la població de Limous / Limoux. Posteriorment, el recorregut anirà cap a Cepies.

Finalment, el recorregut continuarà per la mateixa carretera, anant cap a les localitats de Rofiac d'Aude / Rouffiac d'Aude, Pressia / Prexian i Carcassona / Carcassonne, per on finalitzarà. En aquest tram es farà una nova aturada.

\section{DESCRIPCIÓ DE L’ITINERARI}

Com de costum, estructurarem el recorregut de l'itinerari en una sèrie de PARADES (o d'ESTACIONS), que tot seguit anirem veient. En cadascuna d'aquestes aturades farem un breu comentari (geològic o mineralògic, segons s'escaigui), alhora que indicarem la forma d'arribar-hi en cada cas, tot partint de la parada anterior. Igualment indicarem els trets geològics més representatius, corresponents al trànsit d'una aturada cap a la següent.

Per d'altra banda, en cada cas indicarem, entre parèntesi, el full topogràfic (a escala 1:50.000) on es troba l'aturada. En aquest cas utilitzarem els tres fulls següents de l'IGN (Institut Geographique National, de França), que seran els següents: 2345 (o de Carcassona), 2346 (o de Limoux) i 2347 (o de Quillan). La totalitat de les aturades, es 
realitzarà dintre dels tres fulls acabats d'esmentar, tot i que la quasi totalitat estarà dintre del segon full.

Així doncs, la relació ordenada de les aturades que composen aquest recorregut, és la següent:

PARADA 1 - CONDICIONAL. TRENCALL DE LAVAL, (terme municipal de Quilhan / Quillan, Departament de l'Aude). (Full 2347).

Tot i que el recorregut l'iniciarem al bell mig del poble de Quilhan / Quillan, ens caldrà sortir per la carretera departamental D - 118, anant en el seu sentit septentrional. En arribar a la cruïlla de Laval, farem la primera aturada, després de recórrer uns $2 \mathrm{Km}$, des de l'inici, aproximadament.

En aquest recorregut, hem anat veient afloraments dels materials carbonatats del Cretàcic Inferior, concretament de de l'Aptià i del Clasanyesà, fonamentalment. Aquests materials formen part de làmina d'encavalcament de Quillan, per on ara ens trobem en aquest indret i per on hem circulat fins ara.

PARADA 2 - CONDICIONAL. TRENCALL D'ESPERASAN / ESPÉRASA, (terme municipal d'Esperasan / Espérasa, Departament de l'Aude). (Full 2347).

Després de fer l'aturada anterior, cal continuar per la carretera departamental D118, la qual es va dirigint cap el Nord. Seguint-la, passarem pels voltants del poble de Campanha d'Aude / Campagne - sur - Aude i finalment arribarem al trencall d'on eix la carretera cap a Esperasan / Espérasa. En aquest indret, a uns 4- $5 \mathrm{Km}$ de la parada anterior, en podem efectuar una altra, dintre d'aquest recorregut.

En aquest tram, hem continuat trobant afloraments dels materials mesozoics esmentats a l'aturada anterior. Molt aviat, haurem superat l'encavalcament de la làmina de Quillan i posteriorment començarem a trobar afloraments de les calcaries i calcolutites del Campanià, del Cretàcic Superior, les quals han estat encavalcats per la làmina abans esmentada.

Tot i així, en aquest indret trobarem l'aflorament d'uns nivells de calcolutites rogenques, les quals formen part del Garumnià. Així, aquests són els materials que apareixen a l'indret de l'aturada.

PARADA 3 - CONDICIONAL. TEULERIA DEL TRENCALL DE LUC SUR - AUDE / LUC D“AUDE, (terme municipal de Cuisan / Couiza, 
Departament de l'Aude). (Full 2347).

Després de fer l'aturada anterior, cal continuar el recorregut per la carretera departamental D - 118, anant sempre cap el Nord. Així, aviat s'arribarà al poble de Cuisan / Couiza, que caldrà creuar, superant el trencall del poble d'Arques. Després, seguint cap el Nord, s'arribarà al trencall de Luc - sur - Aude, per la dreta. En aquest indret farem una nova aturada, a uns $4-5 \mathrm{Km}$ de l'anterior.

En aquest recorregut, després de trobar els materials del Garumnià, del transit del Cretàcic al Paleocè, haurem començat a trobar afloraments dels materials cenozoics del Paleocè i de l'Eocè Inferior, fonamentalment de l'Ilerdià i del Tanasià. Aquests darrers són els que es troben a l'indret de la present aturada. Així, per arreu es fan palesos uns afloraments de calcolutites rogenques.

Per d'altra banda, cal dir que hem entrat plenament a la denominada Zona Subpirenaica. Tanmateix, hem acabat de creuar un dels elements estructurals d'aquesta sotsunitat pirinenca: concretament el Sinclinal de Couiza - Arques. Tot i això, abans d'arribar aquí, ja hem creuat altres dues estructures: el Sinclinal de Rennes - les - Bains $i$ $l^{\prime}$ Anticlinal de Puivert - Cardou. De totes formes, aquestes estructures no es fan gaire paleses.

Precisament, pel que respecta als darrers material esmentats (les calcolutites rogenques), cal dir que han estat utilitzats com a matèria prima per a una antiga teuleria que hi havia en aquest indret, prop de la carretera i de la cruïlla on fem l'aturada. Tot i el seu estat, aquesta forma part del Patrimoni Miner.

\section{PARADA 4 - CONDICIONAL. PONT SOBRE EL RIU AUDE, (terme d'Alet / Alet - sur - Bains, Departament de l'Aude). (Full 2347).}

Després de realitzar la parada anterior, cal continuar cap al Nord per la carretera departamental $D-118$. Així, aviat arribarem al trencall que es dirigeix cap el poble d'Alet / Alet - les - Bains (tot i que abans haurem deixat per la dreta el trencall de Terroles). Així, ens caldrà entrar al poble, travessant-lo. A la sortida, farem una nova aturada. prop del pont sobre el riu Aude. I prop de les restes d'uns antics establiments termals. Així, des de la parada anterior, haurem efectuat un recorregut d'uns $5-6 \mathrm{Km}$, per tal d'arribar fins aquest indret.

En aquest recorregut, ens haurem estat sempre desplaçant per la Zona Subpirinenca. Així, haurem trobat inicialment els afloraments dels materials cenozoics esmentats a l'aturada anterior. Tot i així, en superar el Sinclinal de Couiza - Arques $i$ en trobar l'Anticlinal d'Alet, haurem tornat a trobar afloraments del Cretàcic Superior. Aquests són els materials que apareixen a l'indret de la present aturada.

Per d'altra banda, en aquest indret es pot fer una bona observació de la vall del 
riu Aude, per on ens trobem ara situats.

També cal dir, que hi ha unes importants surgències d'aigües bicarbonatades càlciques, epitermals. Aquestes són explotades i embotellades, malgrat el seu contingut en bicarbonat càlcic. Per d'altra banda, aquestes aigües han tingut un cer aprofitament termal, en èpoques passades. Aquesta circumstància va afavorir l'existència d'un important monestir. FOTOGRAFIA 1.

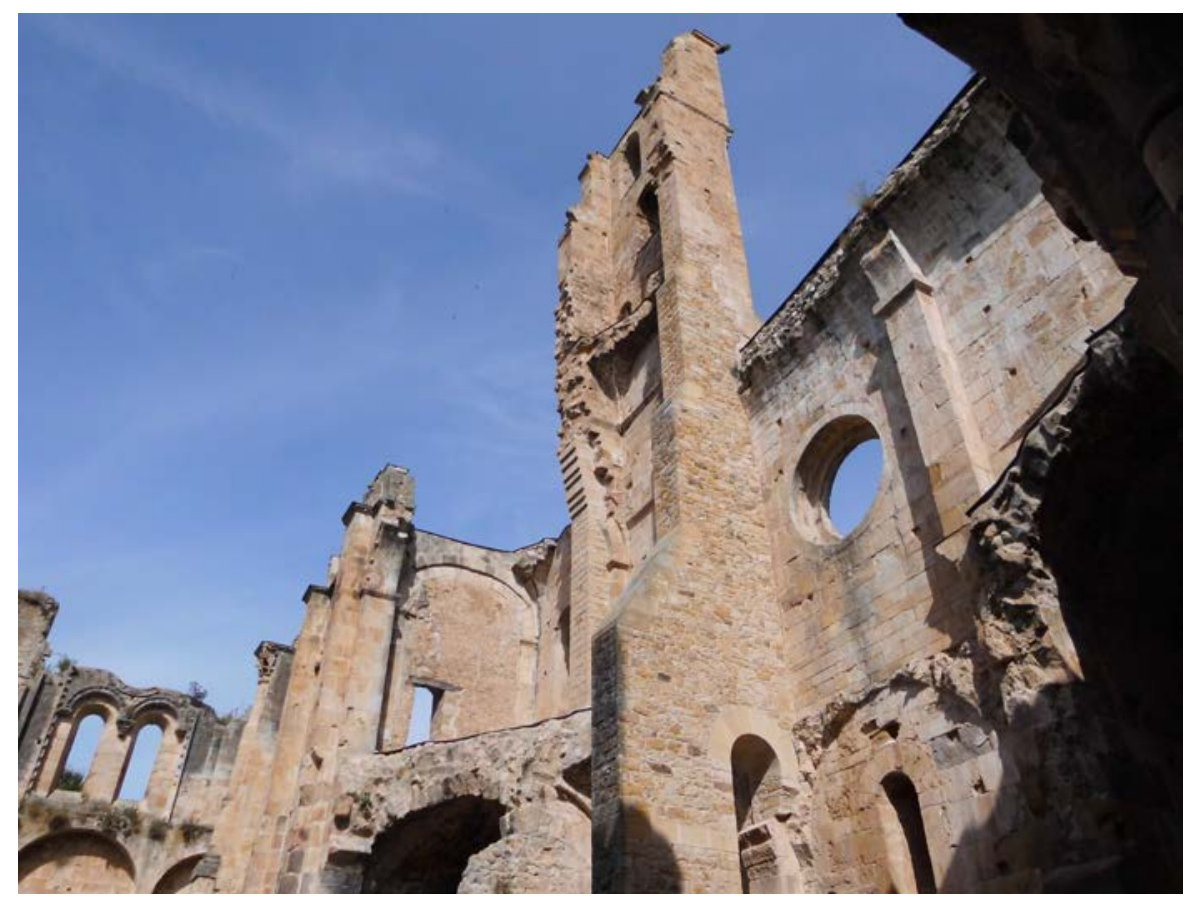

FOTOGRAFIA 1. PARADA 4

Restes de l'Abbaye Notre- Dame - Ancienne Cathedrale d'Alet

PARADA 5 - CONDICIONAL. ANTIGA TEULERIA DE VILLEMARTIN, (terme municipal de Gajan e Viladieus / Gaja - et - Villedieu, Departament de l'Aude). (Full 2346).

Després d'efectuar l'aturada anterior, cal retornar a la carretera D - 118, amb la intenció de continuar cap el Nord, baixant sempre per la vall del riu Aude. Ben aviat arribarem a la població de Limous / Limoux. En arribar-hi, ens convindrà fer una fillola. Així, agafarem la carretera departamental $D$ - 623, la qual es dirigeix cap al NW, cap a Gajan e Viladieus / Gaja - et - Villedieu. A uns $2 \mathrm{Km}$ del seu inici, farem aquesta aturada, a uns 10 de la parada anterior, aproximadament.

En aquest recorregut, hem anat circulant inicialment per la Zona Subpirinenca. Després haurem entrat a la Depressió d’Aquitania (Depressió de Carcassonne) . Així, ara ens trobem amb afloraments dels materials calcolutitics cenozoics. 
Aquests materials han estat emprats com a matèria prima per aquesta antiga teuleria. Finalment, cal dir que tot i el seu estat, forma part del Patrimoni Miner.

PARADA 6 - CONDICIONAL. TEULERIA DE PENNAUTIER, (terme municipal de Puègnautièr / Pennautier, Departament de l'Aude). (Full 2345).

Després de realitzar la parada anterior, cal retornar a Limous / Limoux, per tal de continuar cap el Nord per la carretera D - 118. Així, es passarà per les localitats de Rofiac d'Aude / Rouffiac d'Aude i Pressia / Prexian. Posteriorment s'arribarà a Carcassona / Carcassonne. A partir d'aquí, caldrà seguir per la carretera N-113 (cap a Tolosa / Toulouse). A uns $4 \mathrm{Km}$, es trobarà el trencall de Puègnautièr / Pennautier, des d'on caldrà anar cap a la teuleria. Aquí farem la darrera aturada, a uns $18 \mathrm{Km}$ de la parada anterior.

Com al cas anterior, en aquest recorregut, hem anat circulant pera la Depressió d'Aquitania (Depressió de Carcassonne) . Així, ara ens trobem amb afloraments dels materials calcolutitics cenozoics. Aquests materials han estat emprats com a matèria prima per aquesta antiga teuleria. Finalment, cal dir que tot i el seu estat, forma part del Patrimoni Miner

\section{EN AQUEST INDRET FINALITZA EL RECORREGUT DE L'ITINERARI}

\section{BIBLIOGRAFIA}

BRGM (1970a).- Carte géologique de France a 1/50.000. Fuille d’Ax - les- Termes. Direcction du Service Geéologique et des Labotatoires. Orleans - Source

BRGM (1970a).- Carte géologique de France a 1/50.000. Fuille de Foix. Direcction du Service Geéologique et des Labotatoires. Orleans - Source

BRGM (1970c).- Carte géologique de France a 1/50.000. Fuille de Lavelanet. Direcction du Service Geéologique et des Labotatoires. Orleans - Source

BRGM (1989).- Carte géologique de France a 1/50.000. Fuille de Quillan. Direcction du Service Geéologique et des Labotatoires. Orleans - Source

BRGM (1993).- Carte géologique de France a 1/50.000. Fuille de Carcassonne. Direcction du Service Geéologique et des Labotatoires. Orleans - Source 